http://jmscr.igmpublication.org/home/ ISSN (e)-2347-176x ISSN (p) 2455-0450 crossref DOI: https://dx.doi.org/10.18535/jmscr/v9i11.07

\title{
Molecular docking study on phytochemicals of Azadirachta indica and their derivatives as inhibitors of type 13 - dehydroquinate dehydratase of Salmonella typhi
}

\author{
Authors \\ Dr T. Archana Meena ${ }^{1}$, Dr I. Kannan ${ }^{2 *}$, Dr E. Premalatha ${ }^{3}$, \\ Dr TKV. Sharavanan ${ }^{4}$, Ms. Aishwarya Anbarasan ${ }^{5}$ \\ ${ }^{1}$ Assistant professor of Microbiology, Tagore Medical College and Hospital, Rathinamangalam, \\ Chennai - 600127 \\ ${ }^{2}$ Associate Professor of Microbiology, Tagore Medical College and Hospital, Rathinamangalam, \\ Chennai - 600127 \\ ${ }^{3}$ Professor of Microbiology, Tagore Medical College and Hospital, Rathinamangalam, Chennai - 600127 \\ ${ }^{4}$ Professor and HOD of General Medicine, Tagore Medical College and Hospital, Rathinamangalam, \\ Chennai - 600127 \\ ${ }^{5}$ Final year MBBS student, Tagore Medical College and Hospital, Rathinamangalam, Chennai - 600127
}

\begin{abstract}
Typhoid fever is more prevalent in developing countries due to poor sanitation and inappropriate use of antibiotics leading to the development of drug resistance in the bacteria. S. typhi has Type I 3 dehydroquinate dehydratase, an enzyme involved in the Shikimate pathway, which converts 3dehydroquinate to 3-dehydroshikimate. The inhibition of this enzyme will not allow the bacteria to grow. Hence in the present study an attempt has been done to determine the inhibitor activity of certain phytochemicals and their derivatives from Azadirachta indica docking studies. The 3D structure of the enzyme was downloaded from the RCSB database. The structures of hydroxy pivalic acid [pubchem id 78548], (acetyloxy) acetic acid [pubchem id 83766], germanicol [pubchem id 122857], and phytol [pubchem id 5280435] of Azadirachta indica were obtained from pubchem database. Their derivatives in $2 D$ format were generated with the help of software ACD chemsketch. The docking of ligands was performed using AutoDock vina software using PyRx GUI. The present study concludes that the derivatives of the various phytochemicals of Azadirachta indica can be exploited to identify a potential drug candidate in the treatment of enteric fever.

Keywords: Salmonella typhi, Azadirachta indica, Molecular docking, ADMET properties.
\end{abstract}

\section{Introduction}

Salmonella typhi is a Gram-negative, motile bacilli and a facultative anaerobe belonging to the family Enterobacteriaceae. It causes enteric fever or typhoid fever. Typhoid fever is one of the major public health problems worldwide. It is also a notifiable disease in India. India records around $6,345,776$ cases every year ${ }^{[1]}$. Enteric fever is endemic in all regions of India, making it a huge burden on both government and private healthcare centres $^{[2]}$. Despite the endemicity, intermittent epidemics occur at any point of time in a given 
year. One such epidemic in Maharashtra, India recorded around 9,000 cases in 12 weeks ${ }^{[3]}$.

There are no animal reservoirs for $S$. typhi and hence the common mode of transmission is through the faeco-oral route via water and food contaminated with human faeces. The clinical manifestations of typhoid fever start after an incubation period of 8-14 days ${ }^{[4]}$. Acute typhoid fever is characterized by prolonged step-ladder pattern of fever, bowel disturbances, malaise, headache and anorexia ${ }^{[5]}$. A fraction of the patients also exhibits "rose spots" (exanthems) on the abdomen, chest and back. Complications of the disease may manifest as occult blood in stools, intestinal perforation and peritonitis followed by hypotension, bradycardia, abdominal tenderness and abdominal rigidity. This is associated with high mortality ${ }^{[4]}$.

Salmonella Typhi is a pathogenic serovar of Salmonella which causes typhoid fever in human beings. Recent estimates in 2014 state that approximately 21 million cases and 2,22,000 deaths related to typhoid occur worldwide every year ${ }^{[8]}$. In a study conducted by WHO in 5 Asian countries, it was found that India had 493.35 cases of typhoid per $1,00,000$ population per year in all age groups ${ }^{[9]}$.

The drugs which were originally used to treat typhoid fever include Chloramphenicol, Ampicillin/Amoxicillin and TrimethoprimSulfamethoxazole. However, within two years of its introduction, chloramphenicol resistance became widespread due to its indiscriminate use and was also reported in India a few years later ${ }^{[10]}$. Resistance also started developing to amoxicillin, ampicillin and trimethoprim-sulfamethoxazole and soon, Multidrug-Resistant Typhoid (MDRT) which exhibited resistance to all the first-line drugs started emerging in several countries including India ${ }^{[11]}$.

Following this, Fluoroquinolones like Ciprofloxacin were used as the preferred drug. After a few years, however, resistance to nalidixic acid was detected and failure of ciprofloxacin treatment was reported in several areas ${ }^{[12]}$.
Azithromycin and third-generation cephalosporins like Ceftriaxone were then introduced as treatment for typhoid. Yet, reports about typhoid fever resistant to third-generation cephalosporins have emerged sporadically ${ }^{[13]}$. Also, since azithromycin is a commonly used antimicrobial in India ${ }^{[14]}$, development of $S$. typhi strains resistant to azithromycin treatment might not be surprising. Due to the emergence of widespread resistance to almost all the drugs used in the treatment of typhoid fever, it has become necessary to develop newer drugs for the treatment of typhoid fever.

S. Typhi has Type I 3 dehydroquinate dehydratase, an enzyme involved in the Shikimate pathway, which converts 3-dehydroquinate to 3dehydroshikimate $^{[16]}$. The shikimate pathway is involved in the synthesis of chorismate, which is the precursor for the synthesis of p-hydroxy benzoate, p-amino benzoate and aromatic amino acids like phenylalanine, tyrosine and tryptophan $^{[17]}$. These compounds are essential for survival of the bacteria.

Azadirachta indica, commonly called neem, is a plant with medicinal properties which include antibacterial, antiviral, antimalarial and antifungal properties $^{[18]}$. Recent studies suggest that neem seed extract has specific anti-typhoid activity comparable to that of the drug Ampicillin ${ }^{[19]}$. The fact that the shikimate pathway is absent in humans can be exploited in the development of antimicrobial drugs targeting this pathway, as these drugs will not interfere with normal human metabolism ${ }^{[20]}$. The objective of the present study is to find the potential drug candidate that can inhibit type 1 dehydroquinate dehydratase enzyme from certain alkaloids present in Azadirachta indica plant in the treatment of enteric fever caused by S.Typhi by molecular docking.

\section{Methodology}

\section{Preparation of protein and its binding site}

The three-dimensional structure of type $13-$ dehydroquinate dehydratase enzyme was retrieved from RCSB database (1GQN) (Figure 1). The binding site of the proteins was mapped with help 
of Ligplot+software. The proteins are energy minimized and its water molecules were removed before docking procedure with the help of discovery studiosoftware.

\section{Preparation of ligands}

The structures of hydroxy pivalic acid [pubchem id 78548], (acetyloxy) acetic acid [pubchem id83766], germanicol [pubchemid122857], and phytol [pubchemid 5280435] of Azadirachta indica were obtained from pubchem database (Figure 2). Their derivatives in 2D format were generated with the help of software ACD chem. sketch. The ligands was saved in mol 2 format. The OPEN BABEL software (www.vcclab.org/lab/babel/start.html) was used to convert mol format to PDB format.

\section{Docking study}

The docking of ligands was performed using Auto Dock vina software using PyRx GUI ${ }^{[21,22]}$. Docking was performed to obtain a population of possible conformations and orientations for the ligands at the binding site and also its binding energy and hydrogen bonds. All bonds of ligands were set to be rotatable. All calculations for protein- ligand flexible docking was done using the Lamarckian Genetic Algorithm (LGA) method. The grid box with adimension of $126 \mathrm{x}$ $126 \times 126$ points was used so as to cover the entire binding site of the protein and accommodate ligands to move freely. Then the best conformation was chosen according to hydrogen bonds and the docking wascompleted.

\section{Post docking analysis}

The docked protein-ligand complex was saved in PDB format and was opened with Ligplot+ software ${ }^{[23]}$. The docking poses and bond lengths were analyzed by Pymol software.

\section{Results and Discussion}

The structures of various phytochemicals were downloaded and many derivatives were prepared. These derivatives were then subjected to the docking and further drug likeliness studies.

Table 1: Total energy values of the derivatives obtained by iGEMDOCK and Auto Dock

\begin{tabular}{|l|c|c|}
\hline Ligand & $\begin{array}{c}\text { Total energy - } \\
\text { iGemdock } \\
\text { (Kcal) }\end{array}$ & $\begin{array}{c}\text { Total energy - } \\
\text { Auto Dock } \\
\text { (Kcal) }\end{array}$ \\
\hline 3,3-dihydroxy-2-(hydroxymethyl)-2-methylpropanoic acid & -77.7822 & -5.0 \\
\hline 3-hydroxy-2,2-dimethylpropanoic acid & -80.8946 & -5.4 \\
\hline 2-[(dihydroxyacetyl)oxy]-3-oxobutanoic acid & -88.7074 & -6.2 \\
\hline $\begin{array}{l}\text { (3R,4aS,6aR,6bS,8aR,10R,12aS,12bR,14aR)-10- } \\
\text { hydroxy-2,2,4a,6a,6b,9,9,12a-octamethyl- }\end{array}$ & -117.994 & -12.0 \\
\hline $\begin{array}{l}\text { 2,3,4,4a,5,6,6a,6b,7,8,8a,9,10,11,12,12a,12b,13,14,14a- } \\
\text { icosahydropicene-3-carboxylic acid }\end{array}$ & & \\
\hline $\begin{array}{l}\text { (3R,4aR,6aS,6bR,8aR,12bR,14aR,14bS)- } \\
\text { 4,4,6a,6b,8a,11,11,14b-octamethyl- } \\
\text { 1,2,3,4,4a,5,6,6a,6b,7,8,8a,9,10,11,12b,13,14,14a,14b- } \\
\text { icosahydropicen-3-yl hydrogen carbonate }\end{array}$ & -10.7 \\
\hline $\begin{array}{l}\text { (2E,7S,11R)-3,7,11,15-tetramethylhexadec-2-ene-1,1-diol } \\
\text { (3R,7S,11S,15E)-17-hydroxy-3,7,11,15- }\end{array}$ & \\
\hline tetramethylheptadec-15-enoic acid & -88.3915 & \\
\hline
\end{tabular}


They were subjected to docking studies. Among these derivatives seven were selected based on their binding energies and other binding properties. The selected derivatives and their binding energy values are given in Table 1. The ligand (3R,4aS, 6aR, 6bS, $8 \mathrm{aR}$, 10R,12aS,12bR,14aR)-10-hydroxy-2,2,4a,6a,6b,9, 9,12a-octamethyl 2,3,4,4a,5,6,6a,6b,7,8,8a,9,10, $11,12,12 \mathrm{a}, 12 \mathrm{~b}, 13,14,14 \mathrm{a}-\quad$ icosahydropicene-3carboxylic acid showed an highest binding energy of $-12.0 \mathrm{Kcal}$ and $-117.994 \mathrm{Kcal}$ in AutoDock and iGEMDOCK respectively.
The docking poses of the various ligands with the drug target were analysed with LigPlot+ to study the hydrogen bond length and the aminoacid involved in the bonding (Figure 3 to Figure 6). All the docking poses showed good hydrogen bond length with many aminoacids.

The Table 2 summarises the Lipinski' rule of five. All the selected ligands obey the rule of five which is the prerequisite for drug likeliness.

Table 2: Lipinki's rule of five of the selected ligands

\begin{tabular}{|c|c|c|c|c|}
\hline Ligand & $\begin{array}{l}\text { H- } \\
\text { bond } \\
\text { donors }\end{array}$ & $\begin{array}{r}\text { H-bond } \\
\text { acceptors }\end{array}$ & $\begin{array}{l}\text { Molecular weight } \\
\text { (Da) }\end{array}$ & $\log \mathrm{P}$ \\
\hline 3,3-dihydroxy-2-(hydroxymethyl)-2-methylpropanoic acid & 2 & 5 & 148.037173358 & -0.00 \\
\hline 3-hydroxy-2,2-dimethylpropanoic acid & 3 & 5 & 176.068473486 & -0.14 \\
\hline 2-[(dihydroxyacetyl)oxy]-3-oxobutanoic acid & 3 & 6 & 192.027002598 & -1.70 \\
\hline $\begin{array}{l}\text { (3R,4aS,6aR,6bS,8aR,10R,12aS,12bR,14aR)-10- } \\
\text { hydroxy-2,2,4a,6a,6b,9,9,12a-octamethyl- } \\
\text { 2,3,4,4a,5,6,6a,6b,7,8,8a,9,10,11,12,12a,12b,13,14,14a- } \\
\text { icosahydropicene-3-carboxylic acid }\end{array}$ & 2 & 3 & 470.37599547 & 6.63 \\
\hline $\begin{array}{l}(3 \mathrm{R}, 4 \mathrm{aR}, 6 \mathrm{aS}, 6 \mathrm{bR}, 8 \mathrm{aR}, 12 \mathrm{bR}, 14 \mathrm{aR}, 14 \mathrm{bS})- \\
\text { 4,4,6a,6b,8a,11,11,14b-octamethyl- } \\
\text { 1,2,3,4,4a,5,6,6a,6b,7,8,8a,9,10,11,12b,13,14,14a,14b- } \\
\text { icosahydropicen-3-yl hydrogen carbonate }\end{array}$ & 1 & 2 & 470.37599547 & 8.32 \\
\hline (2E,7S,11R)-3,7,11,15-tetramethylhexadec-2-ene-1,1- diol & 2 & 2 & 312.302830528 & 6.67 \\
\hline $\begin{array}{l}\text { (3R,7S,11S,15E)-17-hydroxy-3,7,11,15- } \\
\text { tetramethylheptadec-15-enoic acid }\end{array}$ & 2 & 3 & 340.297745148 & 6.16 \\
\hline
\end{tabular}

Table 3: ADMET properties of the selected ligands

\begin{tabular}{|c|c|c|c|c|c|}
\hline Ligand & $\begin{array}{c}\text { Blood Brain } \\
\text { Barrier } \\
\text { absorption }\end{array}$ & $\begin{array}{c}\text { Human } \\
\text { Intestinal } \\
\text { absorption } \\
\end{array}$ & $\begin{array}{c}\text { CYP 2C9/2D6/3A4 } \\
\text { substrate }\end{array}$ & $\begin{array}{c}\text { Acute Oral } \\
\text { Toxicity }\end{array}$ & Carcinogenicity \\
\hline 3,3-dihydroxy-2-(hydroxymethyl)-2-methylpropanoic acid & $+(0.9142)$ & $+(0.8538)$ & Non-substrate & $\begin{array}{c}\text { III } \\
(0.5958)\end{array}$ & $\begin{array}{c}\text { Non- carcinogenic } \\
(0.6039)\end{array}$ \\
\hline 2 -[(dihydroxyacetyl)oxy]-3-oxobutanoic acid & $+(0.6947)$ & $-(0.6679)$ & Non-substrate & $\begin{array}{c}\text { III } \\
(0.6756) \\
\end{array}$ & $\begin{array}{c}\text { Non- carcinogenic } \\
(0.6827)\end{array}$ \\
\hline $\begin{array}{l}\text { (3R,4aS,6aR,6bS,8aR,10R,12aS,12bR,14aR)-10- } \\
\text { hydroxy-2,2,4a,6a,6b,9,9,12a-octamethyl- } \\
\text { 2,3,4,4a,5,6,6a,6b,7,8,8a,9,10,11,12,12a,12b,13,14,14a- } \\
\text { icosahydropicene-3-carboxylic acid }\end{array}$ & $+(0.7761)$ & $+(1.0000)$ & $\begin{array}{c}\text { Substrate (CYP } \\
\text { 3A4) }\end{array}$ & $\begin{array}{c}\text { III } \\
(0.8316)\end{array}$ & $\begin{array}{c}\text { Non- carcinogenic } \\
(0.5962)\end{array}$ \\
\hline $\begin{array}{l}\text { (3R,4aR,6aS,6bR,8aR,12bR,14aR,14bS)- } \\
\text { 4,4,6a,6b,8a,11,11,14b-octamethyl- } \\
\text { 1,2,3,4,4a,5,6,6a,6b,7,8,8a,9,10,11,12b,13,14,14a,14b- } \\
\text { icosahydropicen-3-yl hydrogen carbonate }\end{array}$ & $+(0.8824)$ & $+(1.0000)$ & $\begin{array}{c}\text { Substrate (CYP } \\
\text { 3A4) }\end{array}$ & $\begin{array}{c}\text { III } \\
(0.8263)\end{array}$ & $\begin{array}{c}\text { Non- carcinogenic } \\
(0.5599)\end{array}$ \\
\hline (2E,7S,11R)-3,7,11,15-tetramethylhexadec-2-ene-1,1- diol & $+(0.8002)$ & $+(0.8523)$ & Non-substrate & $\begin{array}{c}\text { III } \\
(0.7479)\end{array}$ & $\begin{array}{c}\text { Non- carcinogenic } \\
(0.6748)\end{array}$ \\
\hline
\end{tabular}

The ADMET properties the selected ligands were studied in-silico (Table 3) shows the ADMET properties like blood brain barrier absorption, human intestinal absorption, CYP substrate, acute oral toxicity and carcinogenicity of the selected ligands and all the derivatives has excellent drug likeliness. 


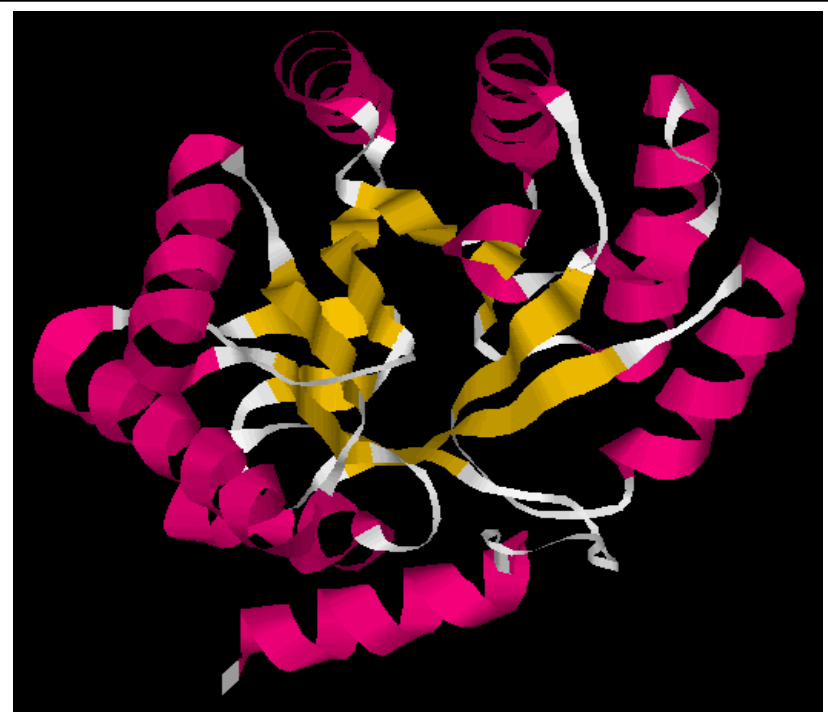

Figure 1: Structure of type 13 - dehydroquinate dehydratase of Salmonella typhi

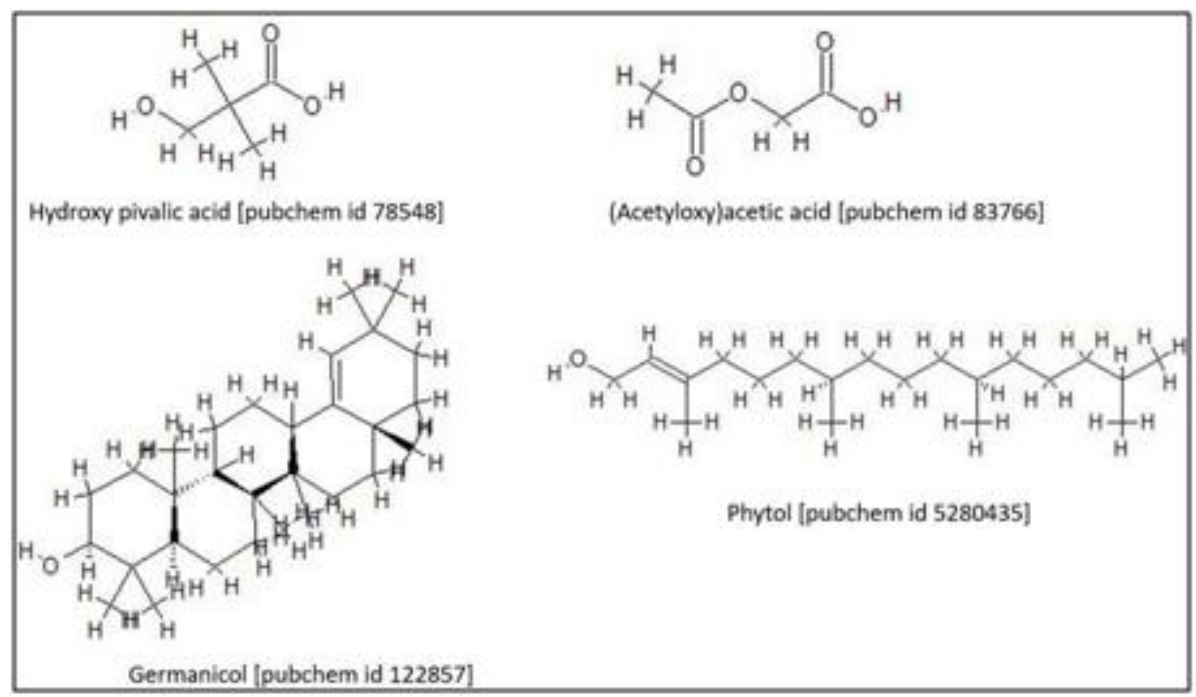

Figure 2: The structure of selected phytochemicals from Azadirachta indica

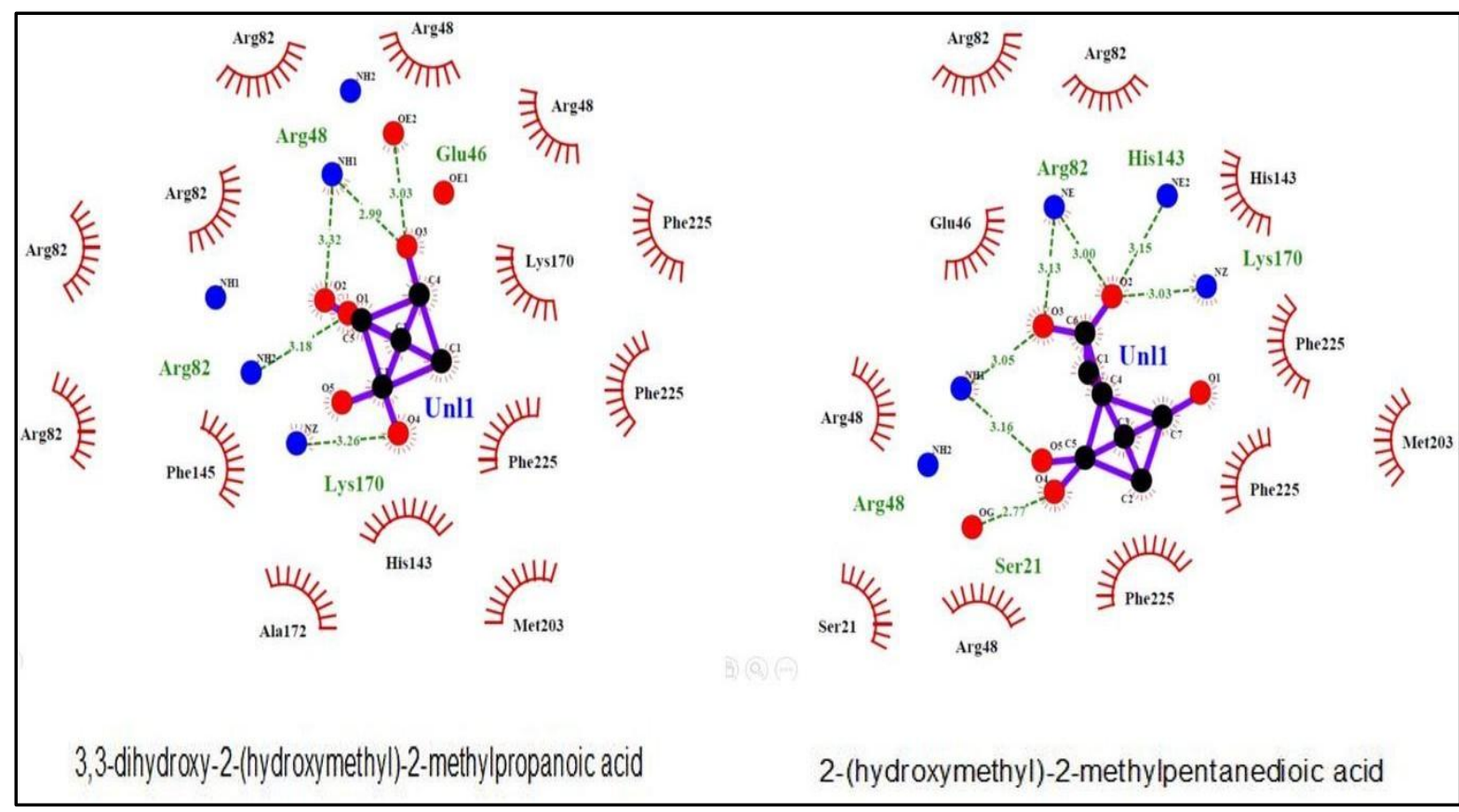

Figure 3 - Docking poses of derivatives of hydroxy pivalic acid 


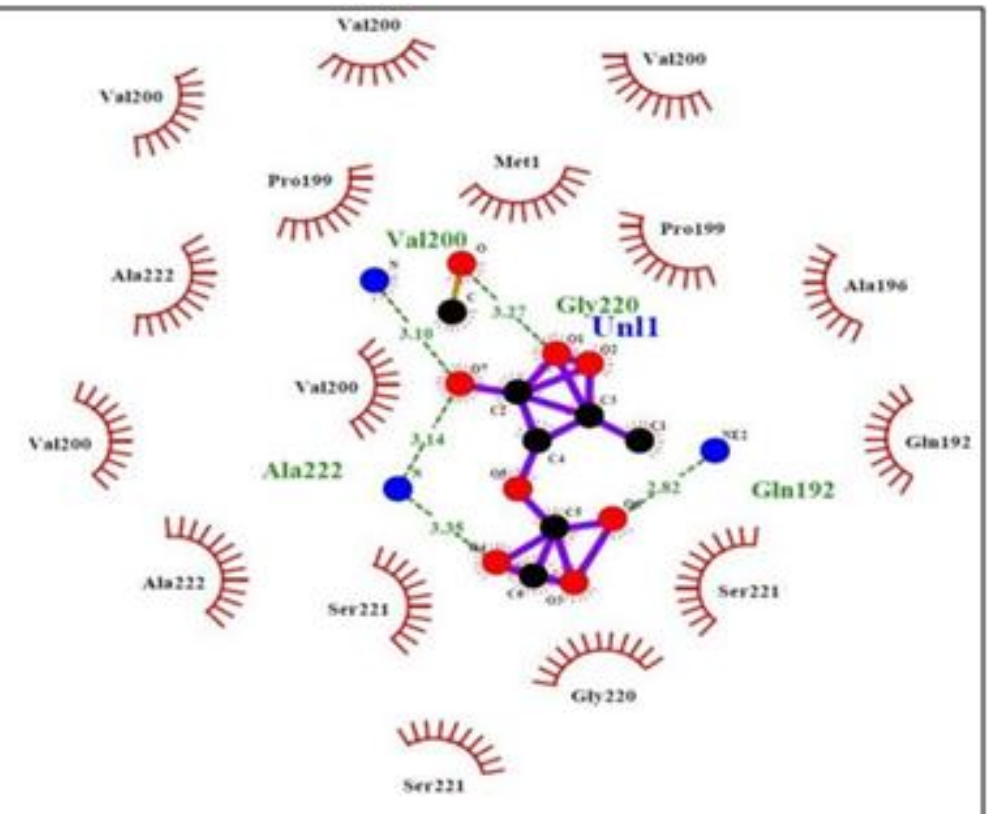

2-[(dihydroxyacetyl)oxy]-3-oxobutanoic acid

Figure 4 - Docking pose of derivative of (acetyloxy) acetic acid

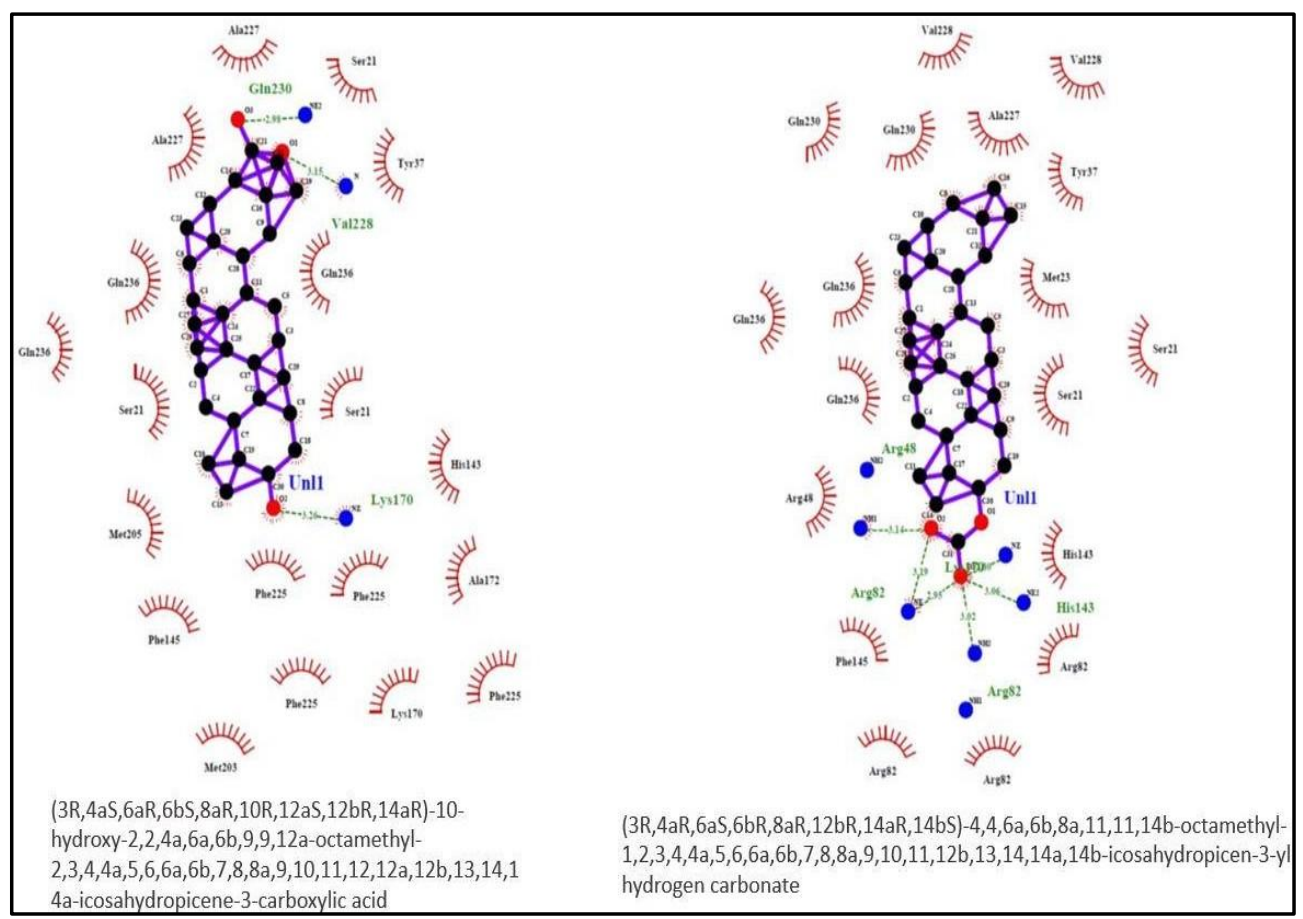

Figure 5 - Docking poses of derivatives of germanicol 


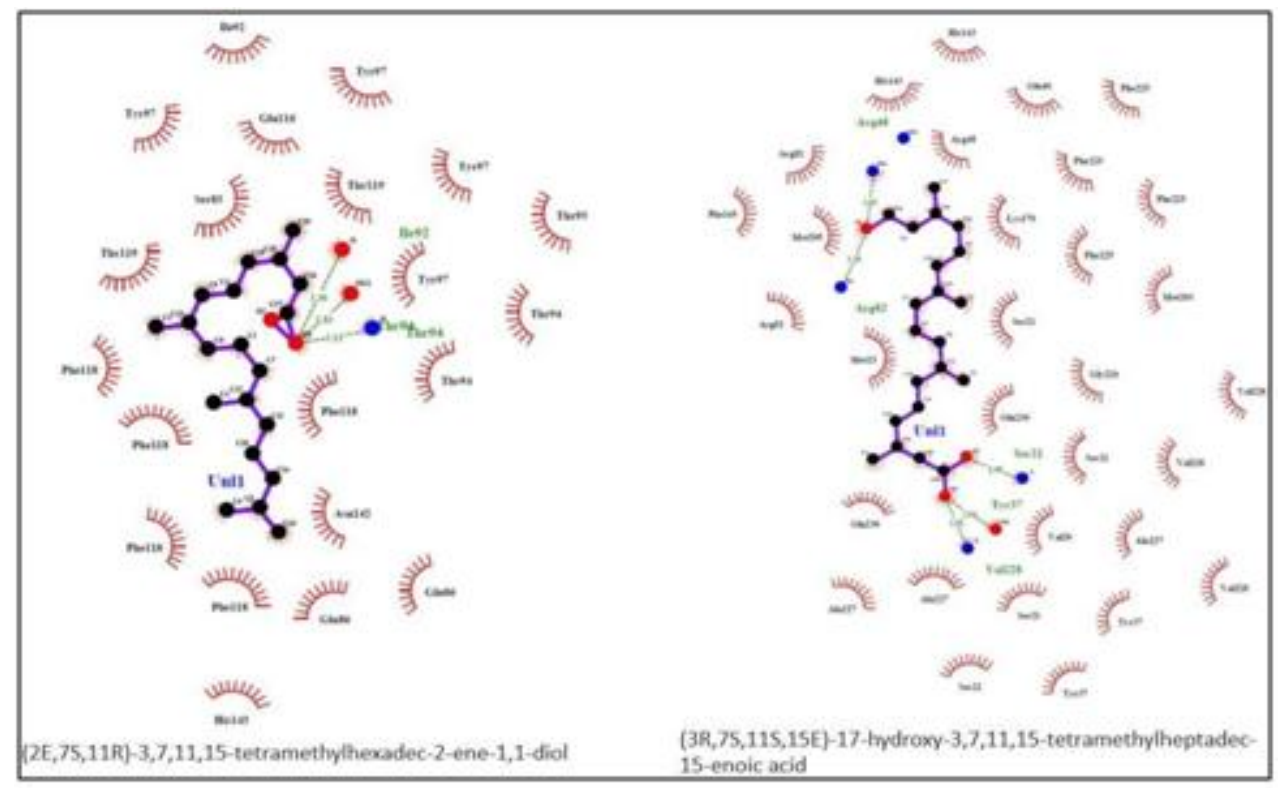

Figure 6 Docking poses of derivatives of phytol

There is an increase in incidence of antibiotic resistance among S.typhi and thus we need some alternative drug strategy that can replace the antibiotics. In the present study, an attempt has been done to find some inhibitors for type 13dehydro quinatede hydratase of Salmonella typhi that can act as a drug instead of antibiotics. The enzyme is well characterised and its threedimensional structure has been identified and is present in the protein database. This has paved way in the discovery of inhibitors for this enzyme which is important for the survival of the bacteria. The antibacterial activity of neem has been well recorded $^{[25]}$. Hence in the present study an attempt has been done to derive drug candidates that can inhibit the growth of bacteria. The derivatives of the various important phytochemicals of neem showed some promising inhibitory activity of the protein target. Thus, the present study gives an insight into the alternative exploration of drugs that can replace the present antibiotics.

\section{Conclusion}

The present study concludes that the derivatives of the various phytochemicals of Azadirachta indica can be exploited to identify a potential drug candidate in the treatment of enteric fever.

\section{References}

1. Crump JA, Mintz ED. Global trends in typhoid and paratyphoid Fever. Clin Infect Dis 2010: 50: 241-246.

2. S. Divyashree, L. E. B. Nabarro, B. Veeraraghavan and P. Rupali. Enteric fever in India: current scenario and future directions. Tropical Medicine and International Health 2016:21:1255

3. Kulkarni AP, Powar RM, Mangalkar SM, Kulkarni VA, Nagalgaonkar RN. Epidemiological investigation of an outbreak of enteric fever in a village in Maharashtra. J Commun Dis 1996: 28:117-121.

4. World Health Organization http://www.who.int/rpc/TFGuideWHO.pdf Retireived 21st January 2018.

5. Akinyemi, K.O., Smith, S. I., Oyefolu, A. O. and Coker, A. O. Multidrug resistance in Salmonella enterica serovar typhi isolated from patients withtyphoid fever complications in Lagos, Nigeria. Public Health, 2005; 119:321-327.

6. "Typhoid Fever" https://www.cdc.gov/typhoid-

fever/index.html May 14, 2013. Retrieved 21 st January2018.

7. Farmakiotis D, Varughese J, Sue P, 
Andrews P, Brimmage M, Dobroszycki J, et al. Typhoid Fever in an inner-city hospital: a 5-year retrospective review. J Travel Med. 2013; 20(1):17-21.

8. World Health Organization http://www.who.int/immunization/diseases /typhoid/en/

9. John Wain, Rene S Hendriksen, Matthew L Mikoleit, Karen H Keddy, R Leon Ochiai. "Typhoid fever" Lancet 2015;385:1136-45.

10. Calquhoun, J. and Weetch, R. S. (1950). Resistance to chloramphenicol developing during treatment of typhoid fever, Lancet 2:621-623.

11. Singhal L, Gupta PK, Kale P, Gautam V, Ray P. Trends in antimicrobial susceptibility of Salmonella Typhi from North India (2001-2012). Indian J Med Microbiol 2014: 32: 149-152.

12. Bhagra S, Kanga A, Ganju SA, Sood A. Antibiotic susceptibility pattern of Salmonella enterica serovar Typhi and Paratyphi a from North India: The changing scenario. Int $\mathrm{J}$ Pharm Bio Sci.2014;5(4):1-9.

13. Kumar, R., and Gupta, N. (2007). Multidrug resistant typhoid fever. The Indian Journal of Pediatrics,74:39-42.

14. Patil KR, Mali RS, Dhangar BK, Bafna PS, Gagarani MB, Bari SB. Assessment of prescribing trends and quality of handwritten prescriptions from rural India. J Pharma Sci Tech 2015: 5:54-60.

15. Raid Al Akeel, Ayesha Mateen, K. Janardhan, V.C. Gupta "Analysis of antibacterial and anti-oxidative activity of Azadirachta indica bark using varioussolvents

extracts"; Saudi Journal of Biological Sciences 2017; 24:11-14

16. Samuel H. Light, George Minasov, Ludmilla Shuvalova, Mark-Eugene Duban, Michael Caffrey, Wayne F. Anderson, and ArnonLavie "Insights into theMechanism of Type I Dehydroquinate Dehydratases from Structures of Reaction Intermediates". The journal of biological chemistry. 2011;286(5):3531-3539.

17. Klaus M. Herrmann "The Shikimate Pathway as an Entry to Aromatic Secondary Metabolism"; Plant Physiol. 1995; 107:7-12

18. Bhowmik D, Chiranjib, Yadav J, Tripathi KK, Sampath KKK. Herbal remedies of Azadirachta indica and its medical application. J. Chem. Pharm. Res. 2010; 2(1):62- 72

19. Somia Gul, Asma Eraj, Zehra Ashraf "Glycyrrhiza glabra and Azadirachta indica against Salmonella Typhi: Herbal Treatment as an Alternative Therapy for Typhoid Fever"; iMedPub Journals Archives of Medicine 2015; 7(6):4

20. Michael Noble, Yugesh Sinha, Aleksey Kolupaev, et al. The kinetic model of the shikimate pathway as a tool to optimize enzyme assays for high-throughput screening. Biotechnology and Bioengineering Journal. 2006;12;43-49.

21. Morris GM, Goodsell DS, Halliday DS, Huey R, Hart WE, Belew R, Olson AJ Automated docking using a lamarckian genetic algorithm and empirical bindingfree energy function. J Comp Chem 1998;19:1639-1662.

22. Trott O, Olson AJ. AutoDock Vina: improving the speed and accuracy of docking with a new scoring function, efficient optimization, and multithreading. J Comp Chem 2010; 31:455-461.

23. Laskowski RA, Swindells MB. LigPlot+: multiple ligand-protein interaction diagrams for drug discovery. J. Chem. Inf. Model., 2011;51:2778-2786.

24. Cheng F1, Li W, Zhou Y, Shen J, Wu Z, Liu G, Lee PW, Tang Y. admetSAR: a comprehensive source and free tool for assessment of chemical ADMET properties. J Chem Inf Model. 2012; 
52(11):3099-105.

25. Thakurta P., Bhowmik P., Mukherjee S., Hajra T.K., Patra A., Bag P.K. Antibacterial, antisecretory and antihemorrhagic activity of Azadirachta indica used to treat cholera and diarrhea in India. J. Ethnopharmacol. 2007;111:607612. 